\section{The distribution of observing responses during two VI schedules*}

\author{
MARC N. BRANCH \\ Laboratory of Psychopharmacology, University of Maryland \\ College Park, Md. 20740
}

Two pigeons were trained to make observing responses during either mixed VI 30-sec EXT or mixed VI 30-sec/VI 120-sec schedules of reinforcement. Observing responses occurred at a higher rate during VI $30 \mathrm{sec}$ than during either EXT or VI $120 \mathrm{sec}$. The results support a hypothesis that observing responses during mixed schedules of reinforcement are reinforced primarily by presentation of a stimulus correlated with the component schedule which provides reinforcement more frequently.

Wyckoff (1952) has defined an observing response as one which presents discriminative stimuli. A response that changes a situation in which a single exteroceptive stimulus is correlated with all component schedules of reinforcement (a mixed schedule) to a situation in which a different exteroceptive stimulus is correlated with each component schedule (a multiple schedule) may be classified as an observing response.

Most investigations of observing responses have been performed using combinations of fixed-ratio and fixed-interval food reinforcement schedules (e.g., Kendall, 1965a,b,c). These schedules generate different patterns and rates of responding, as well as different frequencies of reinforcement. In the present experiment variable-interval (VI) schedules were used. VI schedules, if properly designed, generate homogeneous responding and thus minimize the differences in local rates of responding.

Kelleher (1958) and Kelleher, Riddle, \& Cook (1962) used variable ratio (VR) and extinction (EXT) as component food schedules for the maintenance of observing responses. Although VR schedules can generate relatively constant rates of responding, reinforcement frequency is determined by rate of responding. VI schedules, on the other hand, allow the $\mathrm{E}$ considerable control over the rate of reinforcement.

This experiment represents a first step in separating the relative contributions of differences in patterns and rates of responding and differences in reinforcement frequencies in the maintenance of observing responses.

\section{SUBJECTS}

Two adult male Silver King pigeons, B1 and B3, served as Ss. The birds were

*Preparation of this paper was aided by USPHS Grant No. MH-01604-13 from the National Institute of Mental Health to the University of Maryland. maintained at approximately $80 \%$ of their free-feeding weights throughout the experiment. Both birds had previous training under concurrent schedules of

\section{APPARATUS}

A two-key pigeon chamber (Lehigh Valley Electronics, Model 1519a) was used. Two circular translucent keys, located $22.9 \mathrm{~cm}$ above the floor and $11.4 \mathrm{~cm}$ apart, center to center, were mounted on one wall of the chamber. A solenoid-operated grain hopper was located below and between the keys. Chamber illumination was provided by a $2-\mathrm{W}$ bulb mounted at the top center of the wall on which the keys were mounted. The equipment was monitored and controlled by relay switching and timing equipment, and data were collected on digital counters and two Gerbrands cumulative recorders.

\section{PROCEDURE}

Preliminary Training

The pigeons were exposed to a multiple VI 30-sec EXT schedule of reinforcement on the left key (food key). When VI $30 \mathrm{sec}$ was programmed, the key was red, and when EXT was programmed it was green. Each component was presented for a variable period of time, with a mean time of $105 \mathrm{sec}$. The shortest period was $60 \mathrm{sec}$ and the longest was $120 \mathrm{sec}$. Reinforcement consisted of 3.5-sec access to mixed grain. The right key (observing key) was dark, and pecks on it were recorded but had no programmed consequences. The observing response responding had been established. reinforcement. procedure began when stable rates of
General Procedure

The sequence of experimental manipulations is presented in Table 1 . At the beginning of a session in which the observing procedure was in effect, both keys were illuminated, the food key by a white light and the observing key by an amber light. The component schedules continued to alternate as before. (The schedule on the food key was therefore a mixed schedule.) Five responses on the observing key resulted in a 20-sec presentation of the stimulus correlated with either VI $30 \mathrm{sec}$ or EXT (or VI $120 \mathrm{sec}$ ), depending upon which was currently programmed on the food key, i.e., the food key turned red if VI $30 \mathrm{sec}$ was programmed or green if EXT (or VI $120 \mathrm{sec}$ ) was programmed. The criterion for changing conditions was stable responding for five consecutive experimental sessions except for changing from Phase 3 to Phase 4. Pigeon B3 was exposed to the conditions of Phase 3 for one session. Pigeon B1 remained in Phase 3 for seven sessions.

\section{RESULTS}

The major results are presented in Fig. 1, which shows mean rates of responding on the observing key during Phases 1, 2, 4, and 5 . Nearly $99 \%$ of all responses on the observing key were made while a mixed schedule was in effect on the food key. For this reason the figure depicts the mean rates during times when a mixed food schedule was in effect. Pigeon B3 responded at a higher rate on the observing key during programmed VI $30 \mathrm{sec}$ than during EXT or VI $120 \mathrm{sec}$ during all four phases shown, while Pigeon B 1 showed this same relation in all phases except Phase 2. Pigeon B1 responded at an extremely low rate on the food key during the mixed schedule of Phase 1, so when reinforcement became available according to the VI 120-sec schedule of Phase 2. this bird earned almost all VI 120-sec reinforcements in the presence of the green stimulus. Pigeon B3, on the other hand, had a higher rate on the food key during the mixed schedule and received many of the VI 120-sec reinforcements in the presence of the mixed-schedule stimulus. Under the conditions of Phase 3, Pigeon B3 yielded a typical extinction curve on the observing key in a single session. Pigeon B1 was still responding at a high rate on the observing

Table 1

Sequence of Experimental Conditions

\begin{tabular}{ccccc}
\hline Phase & $\begin{array}{c}\text { Requirement on } \\
\text { Observing Key }\end{array}$ & $\begin{array}{c}\text { Schedule Correlated } \\
\text { With Red }\end{array}$ & $\begin{array}{c}\text { Schedule Correlated } \\
\text { With Green }\end{array}$ & COD \\
\hline 1 & FR 5 & VI $30 \mathrm{Sec}$ & EXT & None \\
2 & FR 5 & VI $30 \mathrm{Sec}$ & VI 120 Sec & None \\
3 & EXT & VI $30 \mathrm{Sec}$ & VI 120 Sec & None \\
4 & FR 5 & VI $30 \mathrm{Sec}$ & VI 120 Sec & None \\
5 & FR 5 & VI $30 \mathrm{Sec}$ & VI 120 Sec & 2 Sec \\
\hline
\end{tabular}



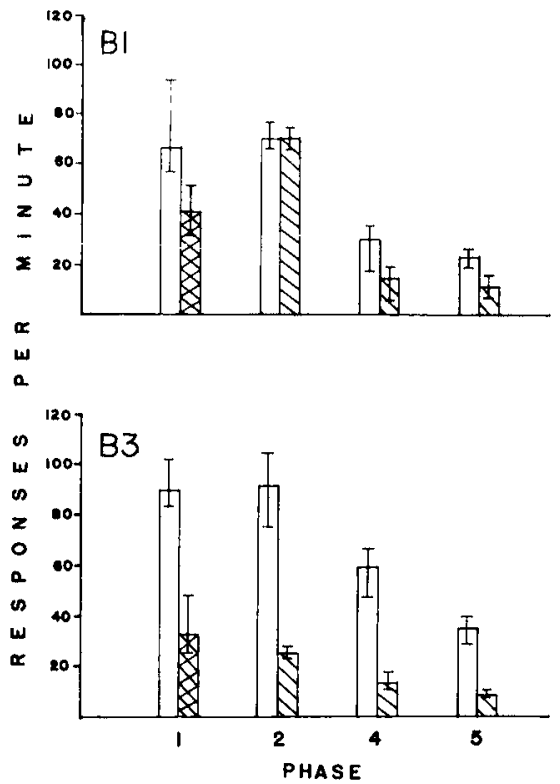

Fig. 1. Mean rates of responding on the observing key during the mixed schedules. Means were calculated using the data from the last 4 days of Phases $1,2,4$, and 5 . Open bars represent means during VI $30 \mathrm{sec}$, cross-hatched bars represent the means during EXT, and hashed bars represent the means during VI $120 \mathrm{sec}$. The vertical lines give the ranges of the means.

key after 7 days of extinction. Following Phase 3 the birds showed qualitatively similar behavior.

Pigeon B1's performance in Phase 3 was interpreted as an indication that part of its behavior on the observing key was being maintained by adventitious correlations between pecks on the observing key and reinforced pecks on the food key. For this reason a changeover delay (COD) of $2 \mathrm{sec}$ was employed in Phase 5 which ensured that reinforcement could not follow pecks on the observing key by less than 2 sec. This contingency had roughly equivalent effects on both birds, lowering their observing rates.

Table 2 shows the relative proportion of time that a multiple was in effect during the last four sessions of Phases 1, 2, 4, and 5 . These values, as well as the rates depicted in Fig. 1, show that after exposure to the conditions of Phase 3 , observing response rates for both birds were reduced.

\section{DISCUSSION}

The distribution of observing responses obtained in the present experiment differs from the distribution reported by Kelleher et al (1962). These investigators found that observing response rate was higher during programmed EXT than during times when VR 100 was programmed. In the present experiment, observing response rates for both Pigeon B1 and Pigeon B3 were reliably higher during programmed VI $30 \mathrm{sec}$ than during EXT or VI $120 \mathrm{sec}$. Kelleher et al explained their results in terms of competing responses. They suggested that "When the mixed stimulus followed the positive stimulus, the VR 100 was probably still in effect; thus, the disposition to respond on the food-producing key was propotent over the disposition to respond on the observing key. As time passed in the presence of the mixed stimulus, it became less probable that the VR 100 period was still in effect; and the disposition to respond on the observing key increased until it became prepotent. When the mixed stimulus followed the negative stimulus, the EXT period was probably still in effect; thus, the disposition to respond on the observing key was prepotent over the disposition to respond on the food-producing key [pp. 12-13]." This competing response explanation is not sufficient to explain the results of the present experiment.

An explanation of the present results can be achieved by hypothesizing that observing responses are reinforced by presentation of the stimulus correlated with the richer of two reinforcement schedules. When the mixed stimulus followed the stimulus correlated with VI $30 \mathrm{sec}$ (positive stimulus), it was probable that the next observing response would produce the positive stimulus. Kendall \& Gibson (1965), in an experiment using fixed-ratio 50 and fixed-interval $2 \mathrm{~min}$ as component food schedules, showed that presentation of the stimulus correlated with fixed-ratio 50 was necessary for the maintenance of observing responses.

An important difference between the present experiment and that by Kelleher et al is that here VI $30 \mathrm{sec}$ was correlated with the positive stimulus, while Kelleher et al had VR 100 associated with the positive stimulus. There is some evidence which suggests that behavior maintained by ratio schedules is somewhat insensitive to interruption by exteroceptive stimuli (Boren, 1961). In the experiment by Kelleher et al, it is possible that once in the presence of the positive stimulus, the birds may have come under the control of stimuli generated by the high rates of responding engendered by the VR 100 schedule. As a consequence, the birds may have "run through" the change from the positive stimulus to the mixed stimulus.

Another important difference is that the rate of alternation of schedules was less rapid in the experiment by Kelleher et al than in the present experiment. In
Table 2

Mean Proportion of Time Spent in the Presence of the Multiple Schedule. Values are means for the last four sessions in each of the phases indicated, and they were calculated by dividing the amount of time spent in the presence of the multiple schedule stimuli by the total time in the session.

\begin{tabular}{ccccc}
\hline & \multicolumn{5}{c}{ Phase } \\
\cline { 2 - 5 } & 1 & 2 & 4 & 5 \\
\hline B1 & 0.770 & 0.815 & 0.548 & 0.491 \\
B3 & 0.755 & 0.730 & 0.622 & 0.531 \\
\hline
\end{tabular}

Kelleher's experiment, the mean duration of each component was 5 min.

In the present experiment, the rate of responding on the observing key during VI $30 \mathrm{sec}$ remained higher than the rate during VI $120 \mathrm{sec}$ after a COD was added in Phase 5. This fact argues against the possibility that the distributions of observing responses obtained here were generated by adventitious food reinforcement.

The reduction in observing response rate after Phase 3 is an indication that in Phases 1 and 2 the mixed stimulus was functioning as a stimulus correlated with a very low rate of reinforcement. In Phases 1 and 2 , both birds had very low rates on the food key during the mixed stimulus and, as a consequence, reinforcement rates were also low during mixed stimulus presentation. The conditions of Phase 3 required that the birds earn all reinforcements in the presence of the mixed schedule stimulus. Exposure to the conditions of Phase 3 apparently increased the strength of responding in the presence of the mixed stimulus.

\section{REFERENCES}

BOREN, J. J. Stimulus probes of the fixed ratio run. Paper presented at the meeting of the Eastern Psychological Association, Philadelphia, 1961.

KELLEHER, R. T. Stimulus-producing responses in chimpanzees. Journal of the Experimental Analysis of Behavior, 1958, 1, 87-102.

KELLEHER, R. T., RIDDLE, W. C., \& COOK, L. Observing responses in pigeons. Journal of the Experimental Analysis of Behavior, 1962, 5 , 3-13.

KENDALL, S. B. Competing behavior and observing responses. Psychonomic Science, 1965a, 3, 279-280.

KENDALL, S. B. An observing response analysis of fixed-ratio discrimination. Psychonomic Science, 1965b, 3, 281-282.

KENDALL, S. B. The distribution of observing responses in a mixed FI-FR schedule. Journal of the Experimental Analysis of Behavior, 1965c, 8, 305-312.

KENDALL, S. B., \& GIBSON, D. A. Effects of discriminative stimulus removal on observing behavior. Psychological Record, 1965, 15, 545-551.

WYCKOFF, L. B., JR. The role of observing responses in discrimination learning: Part I. Psychological Review, 1952, 59, 431-442. 